\title{
Predicting changes in molluscan spatial distributions in mangrove forests in response to sea-level rise
}

\author{
Wei Ma ${ }^{1}$, Mao Wang ${ }^{1}$, Haifeng $\mathrm{Fu}^{1}$, Chaoyi Tang ${ }^{1}$, and Wenqing Wang ${ }^{1}$ \\ ${ }^{1}$ Xiamen University
}

January 12, 2022

\begin{abstract}
Molluscs are an important component of the mangrove ecosystem, and the vertical distributions of molluscan species in this ecosystem are primarily dictated by tidal inundation. Thus, sea-level rise (SLR) may have profound effects on mangrove mollusc communities. Here, we used two dynamic empirical models based on measurements of surface elevation change, sediment accretion and zonation patterns of molluscs to predict changes in molluscan spatial distributions in response to different sealevel rise rates in the mangrove forests of Zhenzhu Bay (Guangxi, China). The change in surface elevation was $4.76-9.61 \mathrm{~mm} \mathrm{a}^{-1}$ during the study period (2016-2020), and the magnitude of surface-elevation change decreased exponentially as original surface elevation increased. Based on our model results, we predicted that mangrove molluscs might successfully adapt to a low rate of SLR (marker-horizon model: $2-4.57 \mathrm{~mm} \mathrm{a}^{-1}$; plate model: $2-5.20 \mathrm{~mm} \mathrm{a}^{-1}$ ) by 2100 , with molluscs moving seaward and those in the lower intertidal zones expanding into newly available zones. However, as SLR rate increased (marker-horizon model: 4.57-8.14 $\mathrm{mm} \mathrm{a}^{-1}$; plate model: $5.20-6.88 \mathrm{~mm} \mathrm{a}^{-1}$ ), our models predicted that surface elevations would decrease beginning in the high intertidal zones and gradually spreading to the low intertidal zones. Finally, at high rates of SLR (marker-horizon model: $8.14-16.00 \mathrm{~mm} \mathrm{a}^{-1}$; plate model: $6.88-16.00 \mathrm{~mm} \mathrm{a}^{-1}$ ), surface elevations were predicted to decrease across the elevation gradient, with molluscs moving landward and species in higher intertidal zones would be blocked by landward barriers. Tidal inundation and the consequent increase in interspecific competition and predation pressure were predicted to threaten the survival of many molluscan groups in higher intertidal zones, especially species at the landward edge of the mangroves. Thus, future efforts to conserve mangrove floral and faunal diversity should prioritize species restricted to landward mangrove areas.
\end{abstract}

\section{Hosted file}

Main Document.docx available at https://authorea.com/users/455132/articles/552520-predictingchanges-in-molluscan-spatial-distributions-in-mangrove-forests-in-response-to-sea-levelrise

\section{Hosted file}

Figures.docx available at https://authorea.com/users/455132/articles/552520-predictingchanges-in-molluscan-spatial-distributions-in-mangrove-forests-in-response-to-sea-levelrise 